\title{
O EXILIO NA METÁFORA \\ (Sobre o Cemitério dos Vivos e as Memórias do Cárcere)
}

Antonio Arnoni Prado

Manhā de 18 de agosto de 1914. Em meio a uma crise de alucinações em que se imaginava lutando contra os soldados do marechal Hermes que o buscavam para por fim a uma série de panfletos anarquistas dirigidos contra o governo, Lima Barreto, depois de dominado pelos familiares e entregue a polícia, é levado para o Hospital Nacional de Alienados. Para ali retornaria ainda uma vez em 1919, ocasião em que, já bastante doente, redige as notas do Diário do Hospúcio, depois enfeixadas no C'emitério dos Vivos.

Noite de 3 de março de 1936. Acusado de supostas ligações com o chamado levante comunista do ano anterior, Graciliano Ramos é preso em sua casa em Maceió. Depois de conduzido a Recife, é embarcado para o Rio de Janeiro, onde permanece sem culpa formada na Colónia Correcional de Dois Rios, na Ilha Grande. Transferido para a Casa de Detenção da rua Frei Caneca, é libertado a 13 de janeiro de 1937 com as anotaçōes para um diário dos seus tormentos, dez anos mais tarde sob o titulo de Memórias do C'árcere

Poucas vezes em nossas letras a perda da liberdade terá exposto de modo tão exemplar a natureza das relações entre o escritor e a obra como no caso desses dois relatos. Em primeiro lugar porque tanto num quanto noutro a impressão é a de estarmos diante de uma redescoberta literária da existencia em que a destruição do homem pressupõe a salvação do escritor, o que - como veremos nos autoriza a dizer que tanto em Lima Barreto quanto em Graciliano

1 As referencias e citaçós deste trabalho npoiam-se, no que se refere a Lima Barreto, na ediç̧ó das Obras Completas (Sto Paulo, Brasiliense, 1956); na parte relativa a Oradllano Ramos, utilizamo-nos da $20^{\circ}$ ediçio das Memórias do Cárcere (Rio-Sfo Paulo, Record, 1985, 2 vol.). Na citaçăo das Memórias, prevaloceu a indicaçáo do tomo em algarismo romano entre parentesis, seguida da página mencionada. 
Ramos a própria busca de um significado para a vida só se configura na recomposição do itinerário da obra, ficando a literatura como o único espaço possivel para desfrutar com plenitude as razóes da discordância.

Nesse sentido, a consciência da marginalização que os aproxima enquanto intelectuais alinhados na contracorrente da história nos permitirá compreender como a linguagem, funcionando no manicomio e no cárcere como um libelo de exclúdo: 1) dialoga com um projeto ficcional que anuncia a sua própria destruiçăo; e 2) retrabalha o empenho ensafstico da memória (o Cemitério dos Vivos, em Lima Barreto; as Memórias do C'árcere, em Graciliano Ramos), amarrando os sintomas da consciência encarcerada ao espectro imaginário do projeto ficcional para depois ajustá-los a uma espécie de estratégia do ressurgimento, que de algum modo supera a realidade com a mesma força com que na ficção de cada um deles as personagens são desfiguradas pelo destino.

Começando por Lima Barreto, imagino que se há um entrada Ideal, esta é justamente o Diário lntimo, que serve de passagem e de roteiro critico entre a biografia e a arte, a índole do homem e o retrato de seus demonios, aproximando o passado e o presente da discriminação e enfeixando-os num autentico breviário dos motivos que antecipam o projeto de fiçãa e, depois, 0 roteiro da obra efetivamente escrita.

No Diário estão os temas que organizam o conjunto da obra e de modo geral estabelecem as direções de seus conflitos, como por exemplo a consciência muito funda das relações entre retórica e opressão; a salda radical pela caricatura, que vê a história como farsa; e a resignação solidarista que compensa a marginalização pela auto-punição e o siléncio.

As implicações da primeira delineiam o impasse do método, quer dizer: a insegurança do que dizer, e de como e por que dizé-lo, sendo pobre e mulato num país de oligarcas e de bacharéis. Muitas são as leituras para a nebulosa das primeiras imagens que fixarão no percurso do escritor o confronto com a ordem letrada que não o reconhecia, fosse como cidadão, fosse como intelectual. A principal é o elo da consciéncia de classe, do jovem que vê a pobreza e a cor atiradas como estigmas e náo ignora que isso impede o sonho (para ele tão caro) da cidadania e da glória numa sociedade cujos códigos deslocavam a literatura e as artes para o espaço fechado da Academia ou para a frivolidade amena dos salōes.

Porém há mais: ao historiar a própria loucura, Lima Barreto fará o relato de seu ingresso simbólico nos domínios da literatura, como se narrar a própria desintegração fosse uma forma de recompor-se e ver brilhar a estrela da metáfora que a vida apagou. "Moço, confessa, - eu não podia apelar para a minha mocidade; ilustrado, não podia fazer valer a minha ilustração; educado, era 
tomado por um vagabundo por todo o mundo e sofria as maiores humilhaçōes" (Cemitério dos Vivos, 176). Buscava por isso um grande choque moral que compensasse a frustração de não ter podido ser escritor com a liberdade de realizar o ideal que tinha na vida (Díario do Hospicio, I, 45). E que apagasse o desespero e a vontade de aniquilar-se em face do horror repentino que o jogava contra a sociedade e a ordem, aquela "vontade de absoluto aniquilamento, mais do que aquele que a morte traz: um desejo de perecimento total da minha memória na terra, um despero por ter sonhado e terem-me acenado com tanta grandeza, e ver agora, de uma hora para outra,... cair tão baixo, que quase me pus a chorar como uma criança" $(\mathrm{CV}, 158)^{2}$

Em oposição a ela, esculpe-se gradualmente no Diário Intimo a fisionomia do pária que alimenta o sonho de escrever, um sonho amadurecido no subúrbio, perto das frustrações que o vão transformando aos poucos numa espécie de ponto luminoso da utopia. Os preconceitos que o excluem da Faculdade; o ressentimento que o faz encolher-se no anonimato dos amunuenses e na miséria da casa paterna, onde o pai, delirante, lhe destruía os planos e o empurrava para o desespero e o álcool; a decisão de exilar-se nas ruas e fugir da tragédia doméstica para casar-se com a literatura em pacto de morte, são apenas os primeiros sinais de uma luta subterranea pela busca da expressão que trouxesse a igualdade, decisiva no ideário do escritor que surgia. Solto, assim, na solidão do diário, o medo social é também estético, ou mais precisamente: o medo de por em papel impresso os seus escritos, - como ele mesmo registra na entrada de 16 de julho de 1908, - é também o medo de ser recusado pelos críticos sob a férula da Academia. "Um crítico, - diz ele então, - não tem absolutamente o direito de injuriar o escritor a quem julgar, seja o livro bom ou mau", justificando que um mau livro muitas vezes faz o bom, e que um crítico sagaz não deve ignorar "um princípio tão fecundo".

Daí que as notas e as reflexões solitárias, particularmente naqueles momentos em que, no hospício, Lima Barreto via destruir-se a imagem do escritor ideal que forjara em sonho, para si mesmo, nas lucubraçōes do Diário Intimo, cultivem a literatura como um bem entre parêntesis, uma espécie de Aleph sublimado que volta e meia retorna feito um símbolo de plenitude nas

O sofrimento leva o autor por vezes a maldizer a sua vocaçăo de escritor. Numa certa altura chega mesmo a dizer que teria sido melhor para ele, mulato e pobre num país de doutores e coronéls, que năo tivesse nascido com essa "compulsáo pelas letras". É quando confessa que gostaria "de viver isolado, fora dessa paixto pela literatura, pelo estudo, ...crelo que ela me faz mal e lastimo nfo ter outra forma de talento em que minha inteligencia pudesse trabalhar" (Diario do Haspicio, 82). 
relaçôes entre o homem e o sonho. É verdade que a vida dizia o contrário, exigindo que a massa dos seus escritos, na forma precária com que era composta, se transformasse num combate de circunstância disputado de má vontade e a pretexto de responder ao veto social e humano que confirmava a sua exclusão. Nesse caso, a impressão que fica é que, nele, o ofício de escrever era um impedimento para si mesmo na medida em que frustrava a extensão inlectual do projeto de origem, claramente desfigurado pela saída caricatural que os tons mais fortes da obra depois confirmaram, a ponto de se constituirem num alvo fácil da crítica, de João Ribeiro para cá.

O fato é que, no centro de sua ficção, como um dos princípios básicos que a organizam, a caricatura do sistema vem sempre desligada do ideal, impondo-se como desenho momentâneo que ajusta o biográfico ao ritmo farsesco de um discurso que se vinga, refletindo a sua própria situação. Disperso na nebulosa inicial do Diário lntimo, entretanto, está o projeto intelectual do escritor que não capitula e que por vezes reaparece no esboço fugaz da pureza de Isalas Caminha em busca das ilusōes que a ideologia anunciava, mas a realidade escondia; nas reflexões do narrador sobre a ingenuidade de Policarpo Quaresma em opor o património espiritual dos livros ao autoritarismo com que as classes dominantes encampavam a República e anunciavam um projeto nacional para o Brasil; ou ainda na educação sentimental do inventor Gonzaga de Sá, que é quase um roteiro autobiográfico sobre a identidade perdida desse visionário sem história que desenha a geografia dos oprimidos na paisagem de um Rio de Janeiro que então a civilização desfigurava.

Tudo isso se perde numa oscilação de extremos que não se tocam. E o que prevalece é a alusão circunstancial como motivo aglutinador da ficção ameaçada: o retrato cruel do poder abusivo de certa imprensa que transforma o Isaras Caminha num romance cifrado da redaçāo do Correio da Manhä, de Eduardo Bittencourt; os desatinos ou o saber impossível do major Quaresma, ele mesmo um arquétipo do burocrata ilustrado a prolongar o positivismo miúdo dos generais de secretaria que o autor tão bem conheceu na intendência da Guerra; as incursões pelo cotidiano que aproximam o registro nervoso das crônicas e dos contos, propiciando os materiais mais bizarros para um painel das mazelas políticas (Numa e Ninfa, Os Bruzundangas), da precariedade das regras sociais (A nova Califórnia, O homem que sabia javaness), e dos valores burlescos que colhia no abandono dos subúrbios, os quais iam do anel de grau das costureiras aos lauréis de penacho das academias da roça.

Vista em seu conjunto, no entanto, a verdade é que a frustração permaneceu, e o fracasso, uma espécie de estigma de quase todas as personagens, de algum modo acompanhou a trajetória do escritor, já então vergado pela miséria e o álcool. A metáfora da plenitude, que prefigurava a liberdade como 
redenção intelectual e humana, esta persistia inalterada. Mais próximo do fim da vida, uns poucos artigos, uma conferéncia frustrada em Mirassol e alguma tentativa de ensaio breve dariam o retoque que faltava à reflexão solitária começada com o Diário Intimo.

O crítico e o ficcionista só se soldariam de fato em 1919, três anos antes da morte, quando Lima Barreto revive na segunda estada no hospício uma espécie de resgate literário da própria obra, então redescoberta no tempo subterrâneo da memória, que agora funde ao destino das personagens o próprio destino do homem, libertos de pensar e de viver. No caso, o hospício é uma espécie de exílio na metáfora ou o limite possivel do delírio anunciado no projeto de origem, mas bloqueado pelas instâncias da ordem. O seu emblema, não sem razāo, é a biblioteca do manicômio, onde Lima Barreto cruza por acaso com os destinos de Dostoievski e Nerval, companheiros de linhagem de um narrador que recria a própria deméncia como forma de identificar-se com a liberdade irreprimida dos desertos, único refúgio em que podia viver com clareza os limites heurísticos da nebulosa inicial do Diário ${ }^{3}$

Conforme o seu próprio relato, esse é o momento inaugural do mergulho que o funde ao mistério pleno da ficção. Neste, o emblema da biblioteca retoma essa contradição inerente à lógica interna da própria metáfora da literatura. Ou seja: um escritor paralisado pela ordem que o cerceia dividindo o texto impossível com os insanos, numa alusão irônica ao seu próprio estrangulamento, ao destino do texto que descarta a lógica dos códigos e que por isso náo pode ser lido. Ausentes os leitores, a obra. - como a biblioteca do hospício, - povoa-se de sombras e de tormentos, recortando por dentro a lógica do delírio que faz a coerência de todas as metáforas (C'emitério dos Vivos, 199). É ali que o narrador ficará, entre os livros e a própria cela, "sentindo bem que aquela biblioteca podia se destinar a tudo, menos à leitura" (CV, 204).

É então que amadurece o sonho do Náutilus perdido na solidão abissal do oceano, onde o Autor acalentará o desejo de converter-se num Capitáo Nemo "fora da humanidade, só ligado a ela pelos livros preciosos, notáveis ou

Numa passagem do Diśrio do Hasprcio, Lima Barreto como que define esse ponto lumínoso no inferno, tomando-o como uma releitura do intelectual decaldo que refaz idealmente a sua imagem no momento em que descobre no sofrimento um viaculo que o amarra ao destino dos escritores a margem. Lembrando-se de lodos os infortúnios que o empurraram para o maniobmio, nos confessa $(X, 104)$ que esses acuntecimentos thes causam apreensós e terror: a natureza deles - espelhos. Espelhos que depois o consolam e recunfortam, quando, recordando as humilhaçós do banho de ducha de chicute (I, 34-5), logo se reporta ao suplicio de Dostolevski e Cervantes, nos quals encontra arrimo e identidade literária, justiflcando a biografia em destroços com o desabafo: "a literatura ou me mata ou me dá o que eu peço dela". 
não, que me houvessem impressionado", totalmente fechado no abandono, ou como ele mesmo diz: "sem ligação sentimental alguma no planeta, vivendo no meu sonho, no mundo estranho que não me compreendia a mágoa (Diário do Hospicio, VIII, 87)

É esse o momento em que se exacerba a tendéncia para as imagens insólitas, as alusōes ou referências fantasmais que atravessam a experiencia de leitura e vêm daí para as reminiscencias do cotidiano. Os Prodigios que lê em Plutarco, por exemplo (visōes de ratos roendo o ouro do templo de Júpiter, raios advertissadores iluminando eclipses em meio a crianças que nascem com cabeça de elefante (DH, X, 109), como que nutrem o desvario do intelectual acossado por vultos estranhos que o levantam a pedir ajuda à polícia (DH, III, 51-2).

Configurando-se embora como um desterro que sublima a sensação de nihilismo intelectual, o hospício, no entanto, transformará de um golpe o escritor. $O$ espetáculo doloroso da loucura, que a princípio the arraigava no espírito uma concepção brumosa em que o mundo mergulhava nas trevas, "sendo unicamente perceptível o sofrimento, a dor, a miséria e a tristeza a envolver tudo", logo se modifica e então lhe parece que ver a vida assim era vê-la bela, já que passa a acreditar que "só o sofrimento, só a dor faziam com que nós nos comunicássemos com o Logos, com a Origem das Coisas e de lá trouxéssemos alguma coisa transcendente e divina" (CV, 163).

Daf talvez o estranho conforto e o inexplicável alento de que se via possufdo dentro das paredes do manicômio. Em mais de uma vez chega a confessar que prefere permanecer entre os loucos a voltar para as incertezas da vida lá fora, como na passagem do Diário do Hospício $(\mathrm{X}, 110)$ em que o vemos retardando a saída apesar da autorização médica para ir para casa, ou mesmo quando, pouco adiante ( $\mathrm{DH}, \mathrm{X}, 115)$ decide confessar que durante todo o tempo que em esteve no manicomio sair ou ficar entre os doentes foram coisas que só dependeram dele: só não ia embora, - esclarece, - porque não sabia morrer.

A razão, no entanto, é que só no hospício logrou retemperar-se e amadurecer uma visão crf́tica do que havia escrito. "Lembrava-me do plano de

4 Dessa perspectiva radical, acusou muitos golpes, quase sempre levados ao exagero de misturar o ressentimento do excluldo com a disciplina necesséria ao cotjdiano do hosplcio. Um dito mais áspero, uma adınoestaçto de rotina jogada ao acaso para refrear impulsos coletivos e quase sempre impessoais, ernm tomados ao pe da letra, como um escárnio, valendo aqui como exemplo o cpisódio de um médico que o trata com a firmeza necessárin à inspogóes, e Lima Barreto se sente diminuldo, entendendo que com essa atitude o médico queria no fundo menosprezar as seus méritos literários (Diário do Haspicio, I, 37). 
minha obra, dos grandes trabalhos que ela demandava, dos estudos que pedia; e, de mim para mim, eu me prometia levá-la a cabo, empregando todos os argumentos, tirando-os de toda parte, não só os lógicos, como os sentimentos; havia de escrevế-la, conclui então, - empregando todos os recursos da dialética da arte de escrever" $(\mathrm{CV}, 183)$.

Esse esforço do narrador encerra a eterna busca de um mesmo fim: Lima Barreto queria viver outra vida amadurecendo o ofício de escrever (DH, II, 45). É que o choque moral que procurava no hospício como que resgatava o lado intelectual do oprimido e o fortalecia em face do opressor. Longe do álcool, reencontrando-se na reflexão e nas leituras, desfruta do gabinete do médico para escrever e sentir-se livre, pressentindo, como um passageiro da utopia, que os ventos e as correntes podiam agora levá-lo de pólo a pólo, das costas da África, às ilhas da Polinésia (CV, 156). É com esse espírito, já concluída a sua obra de ficção, que ele repassa do fim para o começo a trajetória de seus heróis, integrando-se criticamente à perspectiva simbólica de sua verdade. Visto então do ângulo amadurecido do desterro, o seu significado ganha uma nova leitura e a lógica dos fatos, que os pôs fora da vida (Isaías, da sociedade; Quaresma, da pátria; Gonzaga, do próprio mundo), os recupera para uma ação transformadora que paira acima das circunstâncias e, de uma certa forma, os converte em motivos-tópicos da rebeldia contra as forças que os destruíram. Paradoxalmente integrados na interdição do hospício, o seu tempo e de lucidez, decisão que supera a vida tal como está posta, para transcrevê-la na crença solidarista do sonho, agora a coberto de qualquer ameaça.

Em debate recente acerca da obra de Graciliano Ramos, Alfredo Bosi, depois de aludir à solidão que leva esse autor ao extremo de isolar-se de seu grupo ou geração, nos fala de uma linguagem progressista, crítica e pessimista que vem de antes de 1922 e desagua em 1930, a qual, segundo o crítico, sendo de oposição às oligarquias, passa entre outros por Lima Barreto, Monteiro Lobato, Dionélio Machado e chega a Graciliano Ramos ${ }^{5}$

O pessimismo e a solidão, que desde logo fazem pensar no destino de Lima Barreto, revelam em Graciliano, segundo Bosi, uma clara falta de empatia com o mundo, e mais do que isso: uma desconfiança muito marcada em relação à linguagem das classes dominantes. Mas Bosi estranha na marginalização de Graciliano Ramos o que chama de ausência de fusão emotiva com o povo, da perspectiva destas notas exatamente o tipo de adesão que cindiu a 
obra de Lima Barreto, dividido entre a esperança da plenitude da utopia e o relato colhido no flagrante anonimo das incursões pelo cotidiano, que a vida à margem lhe impunha.

O fato a pensar é que em Graciliano a própria linguagem se encarrega de mostrar que não há esperança. Se em Lima Barreto a evoluçăo do projeto humaniza o fracasso através da conversão do narrador ao estoicismo dos deserdados (o homem torturado resgata a queda de seus heróis), em Graciliano Ramos as coisas não se misturam, e o que prevalece é o silêncio. Ou seja: confirmada a impossibilidade de escapar à opressão, o ato de derrogá-la é um gesto radical ou nâo é nada. Dấ a sua recusa em dar voz a determinadas personagens, mesmo repartindo com elas a consciência da espoliação. E também a passividade quase cruel ante a destruição dos valores em jogo (não esboça a menor reação ante a destruiçáo de Madalena pela voracidade de Paulo Honório em São Bernardo, nem tampouco abre alternativas quer à sobrevivência intelectual de Luís da Silva, em Angústia, quer à confirmação da expressividade humana dos retirantes de Vidas Secas, - bem ao contrário do que, por exemplo, faz Lima Barreto no Isaias Caminha, que ressurge num tempo ideal de maturidade para assim recompor a distancia necessária à redenção da queda que lhe apagou o sonho de glória).

No entanto, como Lima Barreto, Graciliano refugia-se do mundo esgueirando-se para o revide do sonho. A exemplo daquele, que purgou no hospício a recompensa de livrar-se dos golpes da vida, a prisão num certo sentido o despojou das amarras do cotidiano (a família, a repartição, o armazém) para de algum modo atirá-lo no coração da metáfora ${ }^{6}$ É comovente vê-lo isolar-se da massa dos detentos, para refugiar-se nos problemas materiais do texto, consertando a sintaxe, reavaliando a propriedade dos termos ou a própria finalidade da obra, mas sobretudo protegendo a valise com as notas do que registrava no navio imundo que descia para o Rio e depois na clausura do Pavilhão dos Primários e da Casa de Detenção.

6 Até mesmo a demisstó do emprego pablico em Alagoas, pressentida através de insinuaçóes e boatos que Ibe chegavam, fol recebida com alivio, dada a necessidade em que Graciliano Ramos se achava de terminar de compor um livro (MC, I, 40-41). A própria ordem de prisáo aflgurava-se-lbe "um principlo de liberdade" (I, 45), que o poria longe das desavenças cada vez malores com a esposa, em nome das quais se aferrava a idéia de ficar isolado, viajar, buscar refoglo. "As minhas armas, fracas e de papel, s6 podiam ser manejadas no isolamento" (1, 52), diz ele a certa alura. Segundo acreditava, um homem inapto para a vida, como ele, só podia ver na pristlo a liberdade para escrever e o alívio das obrlgaçües domésticas $(I, 56)$. 
O resultado, como no C'emitério dos Vivos, é a reflexāo medida que vem da vida para a arte, confirmando nesta o gesto que recusa as regras do opressor, não apenas para fisgá-lo pela via do testemunho simbólico, mas sobretudo para rechaçá-lo na extensão humana da atitude, nos dois autores uma forma inconfundível de resistência.

No caso de Memórias do C'árcere, os motivos que separam a consciência do narrador dos demais protagonistas como que definem o processo de composição, visível por exemplo na articulação reticente com que as cenas resvalam para as sombras; no modo de aludir ao incerto, à desconfiança que cresce por etapas dramáticas que alteram a descrição externa do espaço e a fisionomia moral dos companheiros de infortúnio. Por esse lado, a circularidade do cárcere, como a do hospício, lembra a monotonia asfixiante da caatinga e a marcha das personagens que não avançam. Como na ficção, a desumanização dos retratos é a mesma das impressōes que fixam o movimento dos faxinas e dos soldados, num enquadramento muito próximo do olhar empastado de pessimismo que nivela nos romances o sertanejo e $o$ animal.

Despersonalizado no cárcere, o medo mais afligente é o de perder o domínio da linguagem e o poder da razão (I, 69), o que paradoxalmente não leva o narrador a amaldiçoar o cativeiro, onde pode continuar escrevendo, ao contrário do que aconteceria se fosse devolvido ao mundo de fora. "Lá fora, diria ele mais tarde, - não conseguiria fazer nada" (I, 79). Obstina-se, assim, em desfrutar do inferno como alimento da própria obra, e assume então a resistência como réu sem culpa formada que se antecipa aos movimentos de seu algoz para adivinhar-lhe o proximo golpe.

O confronto da literatura, como no C'emitério dos Vivos, é com a autoridade invisivel: dentro dela, a intuição em pánico e a luta psicológica do narrador para não entregar-se ao inimigo e não compor-se com ele nem mesmo que fosse para pedir-lhe um cigarro. Como o próprio Graciliano confessa: "ser-me-ia possivel, recebendo o favor e os sorrisos, ver com imparcialidade uma personagem?" (II, 211). A verdade é que a consciência cada vez maior de que a opressão se consolidava enquanto sistema (I, III) aguçava o desespero do narrador, que se expõe num auto-retrato como um vulto descarnado, exatamente como, na ficção, descarnava os sentimentos de suas personagens. A vida se encarregava de aproximá-los e assim juntá-los numa outra forma de existencia. "Pouco a pouco vamos caindo no relaxamento. Erguemos a voz, embrutecemos, involuntariamente expomos a rudeza natural que as conveniencias escondem" (I, 117), - eis como surge a eficácia do perseguido que se converte em pária, a exemplo de Lima Barreto no hospício. Como tantos outros, nada mais săo do que 
grãos que um moinho tritura; "ninguém quer saber se resistimos à mó ou se nos pulverizamos logo" (I, 101).

Mas, como no degredo do manicômio, o que avulta no banimento do cárcere é o mergulho solitário na metáfora que empurra o narrador para as imagens do sonho que a vocação lhe ditava, ainda que isso lhe custasse o constrangimento de fechar os olhos aos dramas dos companheiros que purgavam a seu lado o cotidiano da prisão $(1,45)$. É esse o momento em que a adversidade mais ameaça o seu projeto de ficção. De modo ostensivo, é esse o instante em que começa a deslocar para a descrição das próprias sensações os critérios com que organizara a tessitura dramática dos escritos ficcionais. Num certo sentido, o narrador das Memórias do Cárcere como que recupera, de uma perspectiva inversa, o projeto narrativo do escritor Paulo Honório no romance São Bernardo. Perseguidores, ambos, da miragem da literatura, a obra coletiva que Paulo Honónio não alcançou realizar, recompunha-se então na estrutura recorrente das Memórias, carregada de sinais de estilo e de linguagem que evocavam os gritos premonitórios da morte dos escritos de ficção, apurados num diapasão angustiado que afinava o inconformismo. $\mathrm{Na}$ voz do encarcerado que fundia o próprio destino ao de seus personagens, ressovam agora, com outro timbre, a revolta e o encolhimento do intelectual Luís da Silva, o desespero sem remédio do vaqueiro Fabiano e o encurralamento do herói em todos os desfechos. A vida os transformava em bichos (II, 67) e à rotina da desumanização vinha juntar-se a ameaça que rebaixava o escritor, misturado ao criminoso comum e batido pela autoridade $^{7}$

Literariamente, a imagem do homem paralisado no fundo do Letes, funcionando como uma espécie de signo da ruína, confirmava que "a degradação se realizava dentro das normas" (II, 55) e que o confronto com o outro se impunha como um motivo que refletia a própria inferoridade: "éramos cupins no edifício burguês e aplicavam-nos inseticida" (I, 289). À imagem do eu, molambo ou farrapo, corresponde a do outro, caveira ou fantasma, visão de

7 Como autênticos "bichos do subterráneo", na expressão precisa de Anlonio Candich, os presos ora sobem batendo os cascos, ora são contidos pela ferocidade do opressor encolerizado, "espumando nos belços grossos, os bugalhos cluas postas de sangue" "Nío me lembro de focinho mais repulsivo", dirá depols ao anotar as impressỏes de uma noite em que um pobre detento cai nas máos de um soldado cafuso, que o espanca violentnmente ante o siléncio e a Indiferença de todos (II, 67). A vida os transformava em bichos que grunhiam interjeiçóes e perdiam a consciéncin diante de falos como aquele. Bichos humanos oul fantasmas polfticos, observa o narrador, "nío havia lugar para nós... rolarfamos de cárcere em cárcere: nenhuma ulilidade representívamos na ordem nova" (I, 179). 
mundo que aniquila a subjetividade contaminando os processos descritivos que avivam o relato. Nas Memórias do C'árcere, a exemplo das alucinaçōes do Diário do Hospício, o registro das reminiscências está repleto de sombras e figuras estranhas que acenam para o narrador como se ele também fosse um espectro a vagar naquela atmosfera de espantos (II, 15). O esforço para recuperar a identidade perdida é proporcional à obnubilação dos reflexos, que tende a apagar as pessoas e as coisas, fazendo crescer a desconfiança e a capacidade de discerni-las. Rostos familiares são tateados com hesitação e só descobertos através do contorno fluido das máscaras (II, 16), bem ao contrário das imagens do poder cujos traços de barbárie nos são mostrados através da "silhueta recortada em lâmina de faca" (II, 155), a mesma faca do arbítrio que apressará a decisão de revelar ao opressor o projeto de retratá-lo em livro ${ }^{8}$

Já agora, amadurecida no espaço da metáfora, a desforra do narrador é mostrar que se o cárcere lhe roubara o tempo concreto da vida, "no tempo minguado (da ficção) era como se as almas saltassem para fora dos corpos" (II, 172), ressurgindo do isolamento para a plenitude. No escritor que se redescobre toda a ojetividade é pouca para dividir com os que sofrem o reconhecimento de seus algozes. "Não podia encerrar-me no pessimismo, é o que pensa agora, reanimado para a luta; - indispensável regressar à humanidade, fixar-me nela" (II, 298).

Coincidentemente, a exemplo do Lima Barreto que recorta no Policarpo Quaresma a paródia do Brasil autoritário dos tempos de Floriano Peixoto, Graciliano Ramos fixa nos discursos obstinados do revolucionário Agildo Barata uma espécie de desafogo moral, pronto para destruir a barreira do arbítrio da época de Getúlio Vargas. Mas, ao incrustar nos discursos de Agildo alguns signos cortantes (inspirados na faca do arbitrio) como os cristais de gelo $\mathrm{e}$ as unhas do gato, amarrou-os à persistência da aranha (I, 278), imagem que nos permite ligá-lo à obstinação visionária do herói de Lima Barreto, também ele implacável em seu olhar de felino que "tomava por trás das lentes um forte brilho de penetração, como se quisesse ir à al ma da pessoa ou da coisa que fixava".

Silviano Santiago, que trabalhou de modo expressivo em seu romance Em liberdade a condição do escritor sitiado, nos fala, lembrando Barthes, na linguagem como um instrumento de prisåo para o narrador

8 "A culpa é desses cavalos, que mandam para aqui gente que sabe escrever", protestou Indignado o diretor do presídio, ao saber que o narrador decidira redigir um diário da cadeláa nssim que fosse posto em liberdade (MC:, II, 158). 
Graciliano Ramos,, - imagem que aproveitamos aqui como uma espécie de condição de equilíbrio entre o autor e a obra, para justapo-la ao tom ensaistico dos escritos do hospício em Lima Barreto, e ver entáo como tanto num quanto noutro a biografia acaba servindo como um desfecho motivado que amplia a leitura dos esquemas de ficçāo de que depende. Em Lima Barreto para humanizar o sonho marginalizado de seus heróis; em Graciliano Ramos para incorporar à multidão calada dos homens que descreve uma reflexão aguda sobre a própria ruina. 